\title{
Extracorporeal Shockwave Lithotripsy in the Management of a Large Proximal
}

\section{Ureteric Stone: A Case Report}

\author{
Freeg M A H A ${ }^{1}$ Ranade A V², Muttappallymyalil J33, Ghaffar T F A ${ }^{4}$
}

${ }^{1}$ Specialist, Department of Urology, Gulf Medical College Hospital and Research Centre, Ajman, UAE

${ }^{2}$ Research Assistant and Lecturer, Department of Anatomy, Gulf Medical University, Ajman, UAE

${ }^{3}$ Research Associate, Research Division, Gulf Medical University, Ajman, UAE

${ }^{4}$ Specialist, Department of Radio Diagnosis, Gulf Medical College Hospital and Research Centre, Ajman, UAE

\section{Case Report}

\section{Corresponding Author:}

Dr. Anu Vinod Ranade,

Research Assistant and Lecturer, Department of Anatomy, Gulf Medical University, Ajman, UAE.

Email:anuranade@gmail.com

\section{Abstract}

Urinary stone disease still persists as a major health care problem due to its high prevalence. The management of patients with ureteral stones still remains under debate in several areas. There are different therapeutic approaches for ureteral stones depending on stone size, location, anatomical variations of the urogenital tract and patient performance. Extracorporeal shockwave lithotripsy (ESWL) being the main stay of treatment of choice for the stones, the management of large stone remains a point of discussion. With the latest advance in technology coupled with knowledge, there have been recent changes in therapeutic options for ureteric stones. Therefore, the treatment approaches may be individualized in order to achieve optimum outcomes.

This article reports on a case of a large proximal ureteric stone with acute flank pain and hematuria managed by ESWL.

\section{Key Words}

Urinary stone, Ureteric stone, ESWL

\section{Background}

Urolithiasis appears to be a very common disease among

Nepal Journal of Epidemiology 2011;1 (2):70-73

Copyright @ 2010 INEA

Published online by NepJOL-INASP

www.nepjolinfo/index.php/NJE the population of developed countries. It has been estimated that $20 \%$ of the men from the Arabian peninsula (Kuwait, United Arab Emirates and Saudi Arabia), who reach the age of 60 years will have at least one episode in their lives, which is a lifetime risk at least $50 \%$ higher than that of the West ${ }^{1}$. The introduction of ESWL has been the main stay of treatment of urolithiasis including the treatment for the upper tract stones ${ }^{2}$. The recent update shows stone-free rates of $82 \%$ in the proximal ureter (41 studies, 6428 patients), 73\% in mid-ureter (31 studies, 1607 patients) and $74 \%$ in distal ureter (50 studies, 6981 patients) . $^{3}$.

The success rates of the use of ESWL are far from satisfactory and may vary from $80 \%$ in stones smaller than one $\mathrm{cm}$ to five percent in the largest size stones ${ }^{4}$. In selection of a proper treatment modality, it is very essential to know the location, size, and shape of the stone. Previous reports show that ureteral stone-induced pain is closely related to the anatomical structure of the ureter. It has been reported that ureteral stones frequently occur at the following three sites of the ureter: the ureteropelvic junction (UPJ), the ureter crossing external iliac vessel (UEIV) and the ureterovesical junction (UVJ), however other investigators have not ${ }^{5}$. This report describes our experience in the management of a large proximal ureteric stone in the Gulf Medical College Hospital and Research Centre, Ajman, United Arab Emirates.

\section{Case Report and Management}

A 34 year old male driver reported to the outpatient department of Urology of Gulf Medical College Hospital and Research Centre, Ajman, United Arab Emirates on the $10^{\text {th }}$ May 2009 with complaints of left flak pain and bloody urine since one month. Patient reported a past history of stone disease. Clinical examination was unremarkable. Laboratory evaluation revealed $15-18$ red blood cells per high power field and 4-6 pus cells in the urine. Remaining parameters were normal. 
Ultrasound of abdomen and pelvis performed on $14^{\text {th }}$ May 2009 revealed eccogenic shadow at region of left pelviureteral junction with moderately dilated pelvi-calycial system (Fig 1). Multidector - CT scan without contrast showed an oval shaped stone in the upper left ureter of size $2.2 \mathrm{~cm}$. (Fig 2). On $16^{\text {th }}$ July 2009 plain X-ray of urinary track was taken revealed faint calcular shadow in the upper left ureter just above the level of left transverse process of third Lumbar vertebra measuring about $2.2 \mathrm{~cm}$ in size (Fig.3)

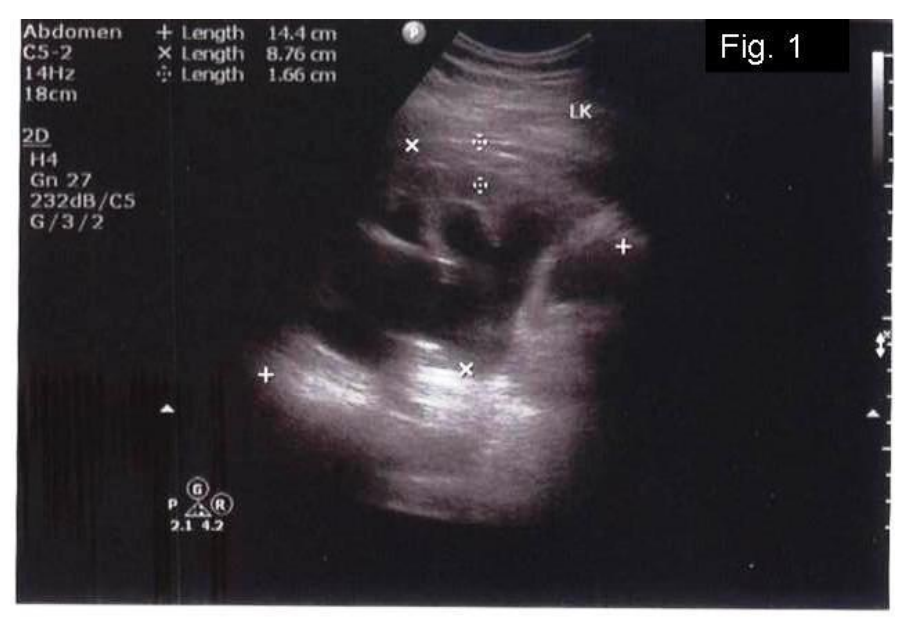

Fig 1: Ultrasound of abdomen and pelvis performed on $14^{\text {th }}$ May 2009 showing an echogenic shadow at region of pelvi ureteric junction with no clear posterior shadowing with moderately dilated pelvicalyceal system.

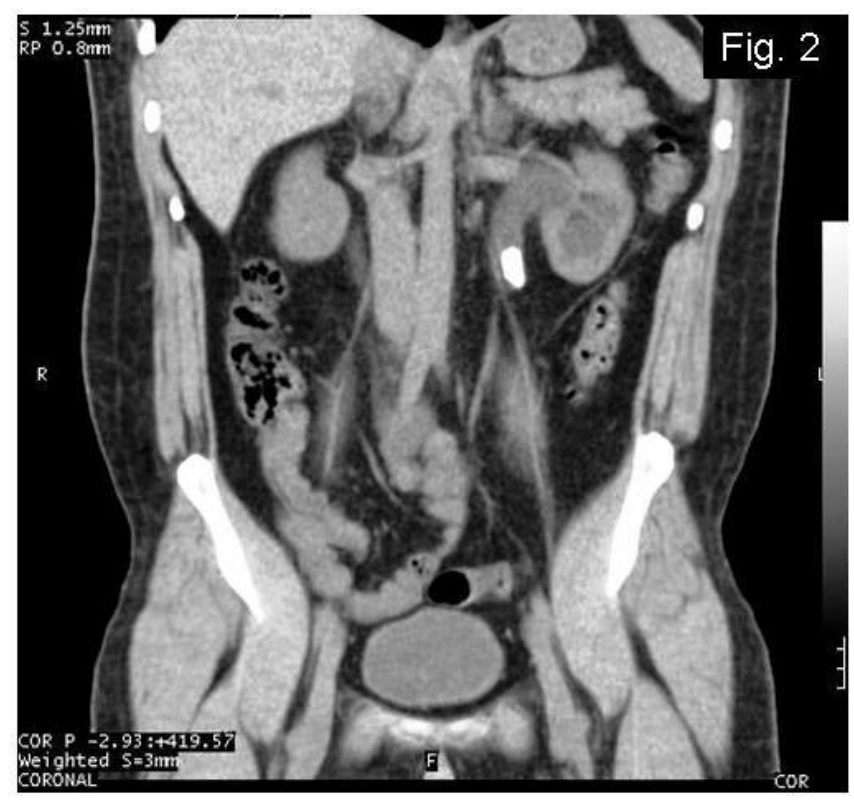

Fig 2: Multi detector CT scan without contrast reveled $2.2 \mathrm{~cm}$ stone at proximal segment of left ureter with moderate pelvicalyceal and proximal ureteric dilatation.

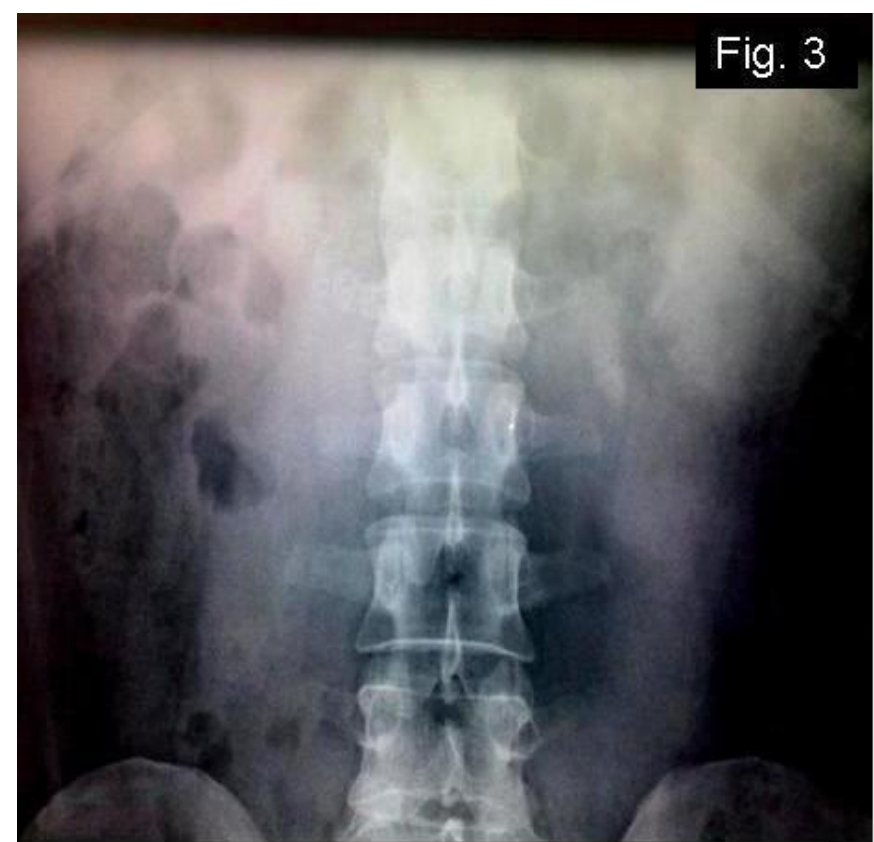

Fig.3: $16^{\text {th }}$ July 2009 plain X-ray of urinary tract showing an oval shaped faintly opaque calcular shadow along the course of proximal lumbar segment of left ureter just above the level of left transverse process of third lumbar vertebra.

Patient underwent ESWL (Siemens Modularis Lithotriptor) on $21^{\text {st }}$ July 2009. A total of 3100 number of shock waves with a maximum energy of 3.5 and a mean energy of 2.9 were delivered in the first session. Plain X- ray of urinary tract was done on $26^{\text {th }}$ July 2009 as part of follow up procedure which showed partial fragmentation of the stone which was seen lodged in the ureter adjacent to the transverse process of the third lumbar vertebra (Fig. 4).

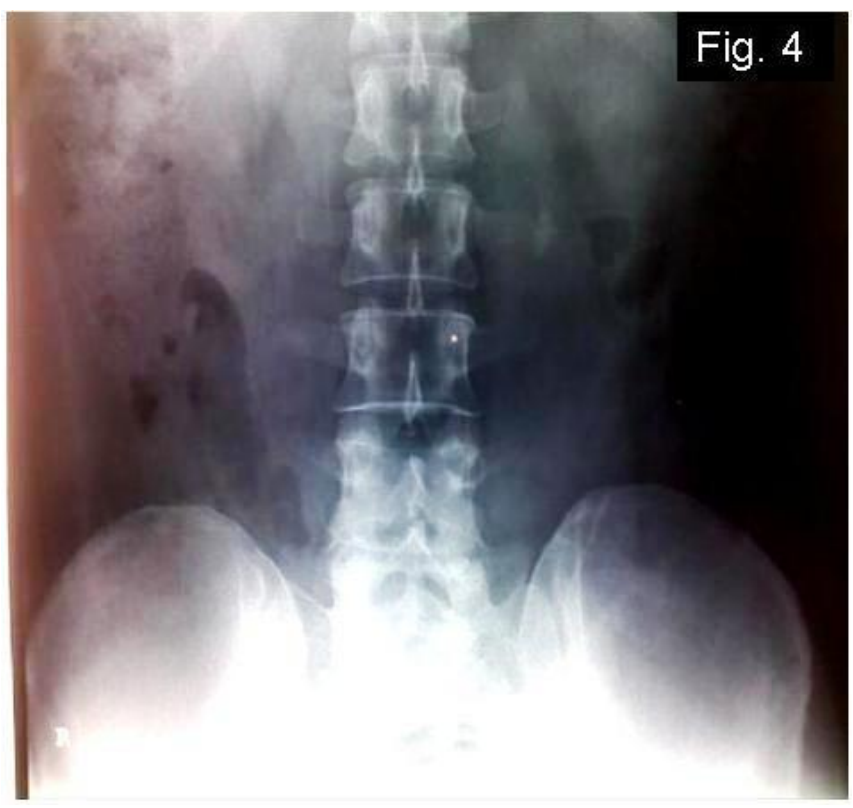

Fig. 4: Plain X- ray urinary tract shows smaller size and lower positioning of the stone at the level of the transverse process of the third lumber vertebra. 


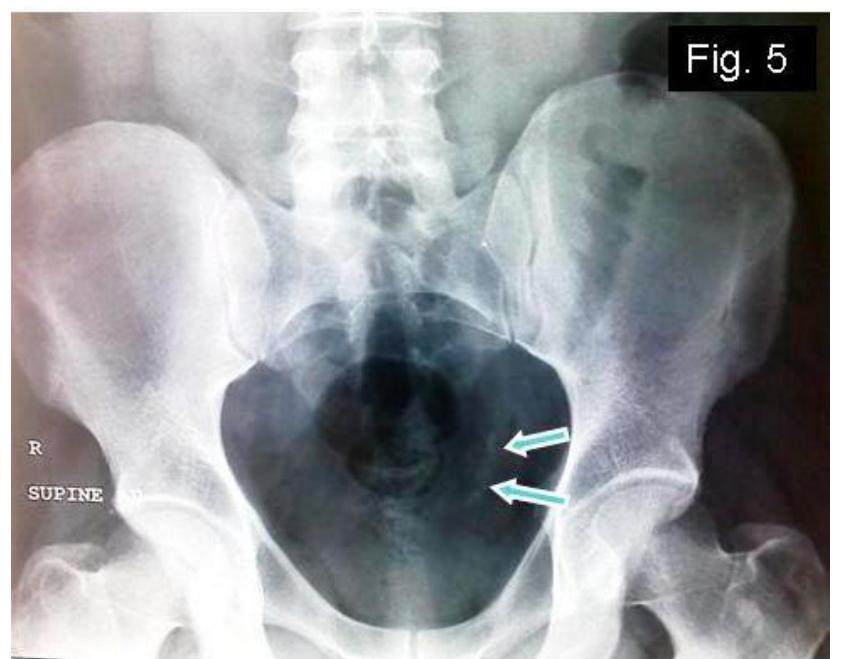

Fig. 5: Plain X- ray of pelvis performed on $8^{\text {th }}$ September 2009 showing multiple small calcular shadows along the course of pelvic segment of the left ureter (stienstrasse)

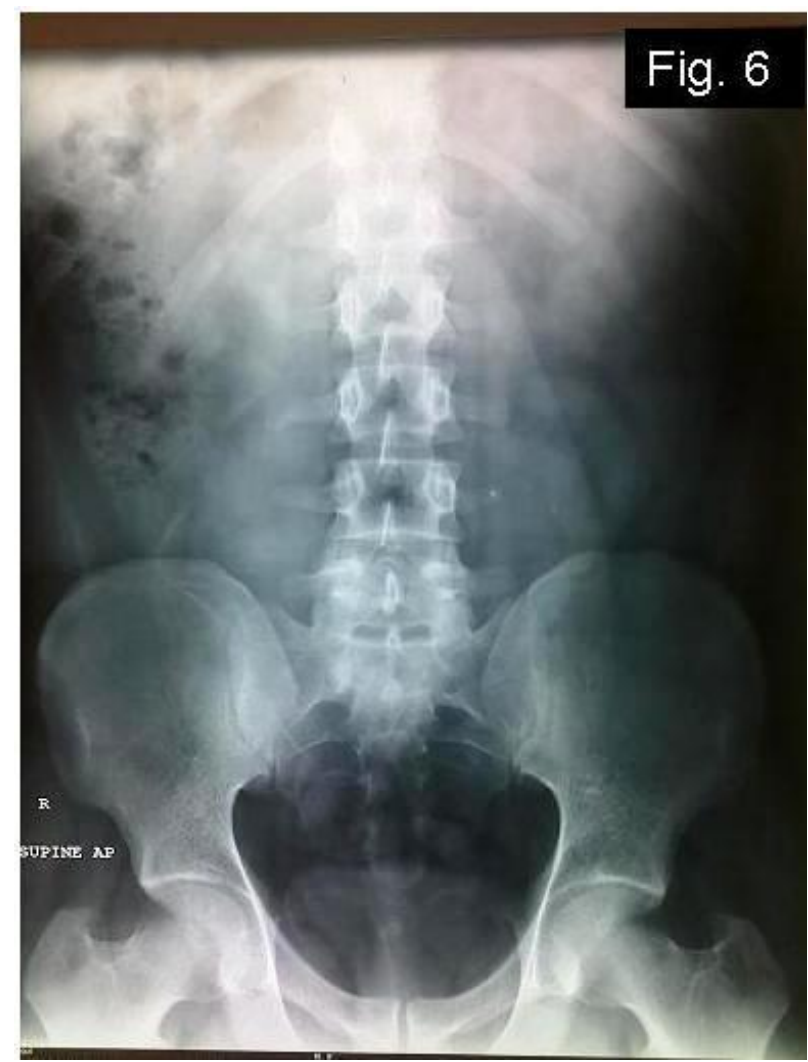

Fig. 6: Follow up X- ray of urinary tract on 19-9-2009 showing no definite radio-opaque calculi (Stone free).

Patient had recurrent episodes of pain. On $8^{\text {th }}$ August 2009, second session of ESWL with a total of 2500 shock waves with a maximum energy of 2.2 and a mean energy of 1.7 were delivered to remove the residual stones. Plain $X$ - ray kidney, ureter and bladder were performed on $8^{\text {th }}$ September 2009 which showed stienstrasse in the lower ureter (Fig. 5). Patient was managed medically by analgesic, anti-inflammatory drugs and advised to take plenty of fluids and Potassium citrate. On the $17^{\text {th }}$ of September 2009, patient reported with acute retention of urine due to stone impacted in the urethra. Foley's catheter was inserted into the urethra and the stone was pushed to the bladder. Catheter was removed on $18^{\text {th }}$ September 2009 there after which the patient complained of dysuria and urgency. Patient was advised to continue with drinking fluids and potassium citrate after which the patient passed multiple small stones of size three to four millimeters. Follow up plain X- ray of kidney, ureter and bladder showed a stone free kidney, ureter and bladder. (Fig. 6)

\section{Discussion}

Shock wave lithotripsy (SWL) is the least invasive treatment for upper urinary tract calculi and is recommended as first line therapy ${ }^{2}$. Stone clearance rates with SWL range from $74 \%$ for stones $<10 \mathrm{~mm}$ to $43 \%$ for those $>10 \mathrm{~mm}^{6}$. Clearance rates for stone located at proximal, mid and distal ureter are $82 \%, 73 \%$ and $74 \%$, respectively. An average of $0.62,0.52$ and 0.37 additional procedure per patient are required for proximal, mid and distal ureteric stone, respectively ${ }^{3}$. SWL has an initial success rate above $80 \%$ for small upper ureteral stones. However, the success rate for large impacted upper ureteral calculi is lower, with the highest rate reported at around $54 \%{ }^{7}$.

The success rate of this treatment is unacceptably low in many patients as these stones may not have a sufficient water-stone interface or a sufficient expansion chamber, both of which are important for fragmentation with $\mathrm{SWL}^{8}$. Eden et al., found stone free rates of $50 \%$ and $11.1 \%$ with SWL for stones $9-12 \mathrm{~mm}$ and $13-16 \mathrm{~mm}$ in diameter, respectively ${ }^{9}$. Studies have shown that this low success rate could also be attributed to the limited number of shock waves in single session and the large size of the stones requiring higher power index ${ }^{10,11}$. Lam et al., found a stone free rate of only $50 \%$ in patients with proximal ureteral calculi that were $1 \mathrm{~cm}$ or greater in diameter ${ }^{6}$.

Variables to consider when choosing a rational treatment approach to ureteral stones include the number of stones and their size, composition, location and the presence of hydronephrosis, and other anatomic factors such as morbid obesity, presence of a solitary kidney, strictures and ureteral anomalies $^{12,13}$. Of all these factors, stone size and location are now thought to be the most important factor and plays an important role in the choice of treatment modality and outcomes. Reports show that overall, there was no difference in stone-free rates between SWL and Ureteroscopy (URS) for stones in the proximal ureter $(n=$ 8670 ). However, for proximal ureteral stones of $<10 \mathrm{~mm}$ ( $n$ = 1129), SWL had a higher stone-free rate compared to URS, and for stones size of $>10 \mathrm{~mm}(n=523)$, URS had a superior stone-free rate. This difference was due to the stone-free rate for proximal ureteral stones treated with URS did not significantly vary with size, whereas the stone-free rate following SWL was negatively correlated with stone size ${ }^{3}$.

Single ureteral stone has no consensus on how many sessions of ESWL should be tried before other treatment modalities are offered. According to Kim et al., the cumulative stone-free rates after SWL sessions 1 to 3 were $64 \%, 81 \%$, and $88 \%$ respectively ${ }^{14}$. Pace et al., reported that, 
in their study, the stone-free rate after the initial SWL was $68 \%$, decreased to $46 \%$ after the second re-treatment, and decreased further to $31 \%$ after the third re-treatment ${ }^{15}$. The cumulative stone-free rate was $77 \%$ after 2 treatments, and $77 \%$ after 3 treatments. Thus they proposed that this trend might be related to stone composition, stone size, and the presence of ureteral stenting and therefore, they recommended early intervention with ureteroscopy after iniitial ESWL failure, especially when the stone size was $>10$ $\mathrm{mm}$. Many patients have to undergo 2 or more shockwave sessions for a complete stone disintegration ${ }^{16}$. Reports on the success rate of repeat SWL after failed initial treatment is relatively low ${ }^{15}$.

The effect of hydronephrosis in patients with proximal ureteral stones affecting the outcome in ESWL treatment still remains controversial. In our case the patient was presented with hydronephrosis prior to ESWL treatment and we were able to achieve stone clearance in $40 \%$ with 3 $4 \mathrm{~mm}$ residual fragments after one month follow up. These results are in accordance with findings from Singh et al. that neither the presence nor the degree of hydronephrosis had a significant impact on time to stone clearance or success rates ${ }^{10}$.According to the guidelines of the American Urological Association, there are four available methods that can be used for treatment of large proximal ureteral calculi: (1) open surgery, (2) percutaneous nephrolithotomy, (3) ureteroscopy, and (4) ESWL. Management of urethral calculi varies according to site and size and associated urethral disease. Retrograde manipulation into the urinary bladder following litholapaxy or lithotripsy is a frequent procedure for posterior urethral calculi ${ }^{16}$. Failure to recognize and to remove an obstructing urethral stone can lead to a host of complications, such as postobstructive renal failure, long-term urethral damage, urethrocutaneous fistulas, incontinence and impotence ${ }^{17}$.

\section{Conclusion:}

In conclusion, this case is important to report because the management of large upper ureteric stone more than $2 \mathrm{~cm}$ is very critical. ESWL for treatment of large upper ureteric stone more than $2 \mathrm{~cm}$ is optional and alternative to other modalities such as open ureterolithotomy or percutaneous nephrolithotomy or retrograde uretroscopy. It is effective in clearing stones, well tolerated by patients and induces relatively minor complications. However, multiple sessions may be needed. In a country like UAE, where urolithiasis is rampant, follow up in evaluating the patient is highly recommended.

\section{References}

1. Robertson WG, Walker VR, Hughes $H$, Husain I and EIFaqih SR. Renal stone disease in the Middle East. In: Hatano $\mathrm{M}$ et al (ed). Nephrology Vol 1. Tokyo; Springer-Verlag, 1991:815-22.

2. Lottmann H, Gagnadoux MF, Daudon M. Urolithiasis in children. In: Gearhart JP, ed. Pediatric Urology, Philadephia:
Elsevier Saunders; 2001: Chapt 52, p 839.

3. Preminger GM, Tiselius HG, Assimos DG, Alken P, Buck AC, Gallucci M, et al. 2007 Guideline for the management of ureteral calculi. Eur Urol 2007;52(6):1610-31.

4. Vega Vega A, de Blas Gómez V, Guerreiro González R, Gallo Rolanía FJ. [Single center experience with Siemens Lithostar Modularis for treatment of 1500 solitiary urinary stones]. Actas Urol Esp 2008 ;32(5):546-51.

5. Eisner BH, Reese A, Sheth S, Stoller ML. Ureteral stone location at emergency room presentation with colic. J Urol $2009 ; 182(1): 165-8$.

6. Lam JS, Greene TD, Gupta M. Treatment of proximal ureteral calculi: holmium:YAG laser ureterolithotripsy versus extracorporeal shock wave lithotripsy. J Urol 2002 ;167(5):1972-6.

7.Wu CF, Shee JJ, Lin WY, Lin CL, Chen CS. Comparison between extracorporeal shock wave lithotripsy and semirigid ureterorenoscope with holmium:YAG laser lithotripsy for treating large proximal ureteral stones. J Urol $2004 ; 172(5): 1899-902$.

8. Tunc L, Kupeli B, Senocak C, Alkibay T, Sözen S, Karaoglan $U$, et al. Pneumatic lithotripsy for large ureteral stones: is it the first line treatment? . Int Urol Nephrol 2007;39(3):75964.

9. Eden CG, Mark IR, Gupta RR, Eastman J, Shrotri NC, Tiptaft RC. Intracorporeal or extracorporeal lithotripsy for distal ureteral calculi? Effect of stone size and multiplicity on success rates. J Endourol 1998;12(4):307-12.

10. Singh I, Gupta NP, Hemal AK, Dogra PN, Ansari MS, Seth $A$, et al. Impact of power index, hydroureteronephrosis, stone size, and composition on the efficacy of in situ boosted ESWL for primary proximal ureteral calculi. Urology $2001 ; 58(1): 16-22$.

11. Coz F, Orvieto M, Bustos M, Lyng R, Stein C, Hinrichs A, et al. Extracorporeal shockwave lithotripsy of 2000 urinary calculi with the modulith SL-20: success and failure according to size and location of stones. J Endourol 2000 ;14(3):239-46.

12. Lingeman JE, Shirrell WL, Newman DM, Mosbaugh PG, Steele RE, Woods JR. Management of upper ureteral calculi with extracorporeal shock wave lithotripsy. J Urol 1987 ;138(4):720-3.

13. Dretler SP. Ureteral stone disease. Options for management. Urol Clin North Am 1990 ;17(1):217-30.

14. Kim HH, Lee JH, Park MS, Lee SE, Kim SW. In situ extracorporeal shockwave lithotripsy for ureteral calculi: investigation of factors influencing stone fragmentation and appropriate number of sessions for changing treatment modality. Endourol 1996;10(6):501-5.

15. Pace KT, Weir MJ, Tariq N, Honey RJ. Low success rate of repeat shock wave lithotripsy for ureteral stones after failed initial treatment. J Urol 2000 ;164(6):1905-7.

16. Koga S, Arakaki Y, Matsuoka M, Ohyama C. Urethral calculi. Br J Urol $1990 ; 65(3): 288-9$.

17. Kaplan M, Atakan IH, Kaya E, Aktoz T, Inci O. Giant prostatic urethral calculus associated with urethrocutaneous fistula. Int J Urol 2006 ;13(5):643-4. 